\title{
Management of complex pleural disease in the critically ill patient
}

\author{
Kurt Hu ${ }^{1}$, Amit Chopra ${ }^{2}$, Jonathan Kurman ${ }^{1}$, J. Terrill Huggins ${ }^{3}$ \\ ${ }^{1}$ Division of Pulmonary and Critical Care Medicine, Medical College of Wisconsin, Milwaukee, WI, USA; ${ }^{2}$ Division of Pulmonary and Critical \\ Care Medicine, Albany Medical College, Albany, NY, USA; ${ }^{3}$ Division of Pulmonary, Critical Care, and Sleep Medicine, Medical University of South \\ Carolina, Charleston, SC, USA \\ Contributions: (I) Conception and design: All authors; (II) Administrative support: All authors; (III) Provision of study materials or patients: All \\ authors; (IV) Collection and assembly of data: All authors; (V) Data analysis and interpretation: All authors; (VI) Manuscript writing: All authors; (VII) \\ Final approval of manuscript: All authors. \\ Correspondence to: Kurt Hu. Assistant Professor of Medicine, Division of Pulmonary and Critical Care Medicine, 8701 Watertown Plank Road, \\ Milwaukee, WI 53226, USA. Email: kuhu@mcw.edu.
}

\begin{abstract}
Disorders of the pleural space are quite common in the critically ill patient. They are generally associated with the underlying illness. It is sometimes difficult to assess for pleural space disorders in the ICU given the instability of some patients. Although the portable chest X-ray remains the primary modality of diagnosis for pleural disorders in the ICU. It can be nonspecific and may miss subtle findings. Ultrasound has become a useful tool to the bedside clinician to aid in diagnosis and management of pleural disease. The majority of pleural space disorders resolve as the patient's illness improves. There remain a few pleural processes that need specific therapies. While uncomplicated parapneumonic effusions do not have their own treatments. Those that progress to become a complex infected pleural space can have its individual complexity in therapy. Chest tube drainage remains the cornerstone in therapy. The use of intrapleural fibrinolytics has decreased the need for surgical referral. A large hemothorax or pneumothorax in patients admitted to the ICU represent medical emergencies and require emergent action. In this review we focus on the management of commonly encountered complex pleural space disorders in critically ill patients such as complicated pleural space infections, hemothoraces and pneumothoraces.
\end{abstract}

Keywords: Pleural disease; empyema; pneumothorax; hemothorax; pleural effusion of extra vascular origin; criticall illness

Submitted Mar 01, 2021. Accepted for publication Jun 21, 2021.

doi: $10.21037 /$ jtd-2021-31

View this article at: https://dx.doi.org/10.21037/jtd-2021-31

\section{Introduction}

Pleural disorders are common in the intensive care unit (ICU). While most pleural disorders occur concurrently through the course of the illness, occasionally, pleural disorders can be the primary reason for an ICU admission. Some pleural diseases, such as complicated parapneumonic effusions (CPEs), hemothorax, and pneumothorax, can often be challenging to manage and may require expert consultation. In this manuscript, we will review the management of complex pleural space infections, hemothorax, and pneumothorax in the critically ill patient.

\section{Infected pleural space}

An infected pleural space can be further classified into simple parapneumonic effusions, CPE, empyema, infected bronchopleural fistula, and empyema necessitans. These can be seen in the setting of pneumonia, hematogenous spread, penetrating trauma, or as a result of surgery.

\section{Definition}

Parapneumonic effusions result from pneumonia, lung abscess, or bronchiectasis (1). While CPE is defined by 
Table 1 Characteristic findings of the spectrum of parapneumonic effusions

\begin{tabular}{lccc}
\hline Characteristics & Uncomplicated parapneumonic effusion & Complicated parapneumonic effusion & Empyema \\
\hline Appearance & Turbid & Cloudy & Purulent \\
$\mathrm{pH}$ & $>7.30$ & $<7.20$ & $\mathrm{NA}$ \\
Glucose level, mg/dL & $>60$ & $<60$ & NA \\
LDH, U/L & $<700$ & $>1000$ & NA \\
Gram stain & Negative & May be positive & Positive \\
\hline
\end{tabular}

LDH, lactic acid dehydrogenase; NA, not applicable.
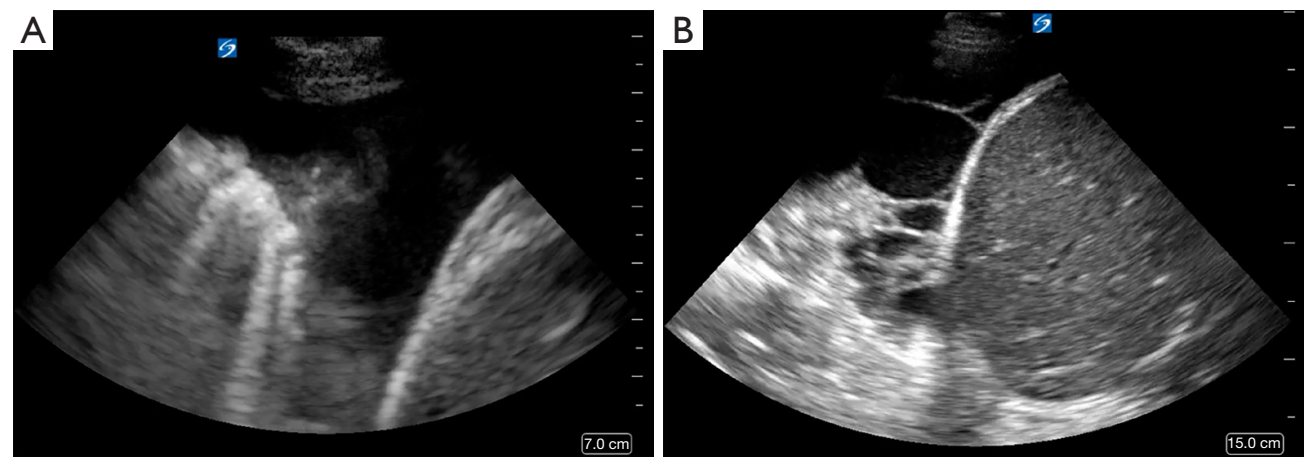

Figure 1 (A) Simple appearance on ultrasound evaluation. This requires diagnostic thoracentesis (Video 1). (B) Complex appearance on ultrasound evaluation. This requires chest tube drainage (Video 2).

the criteria as outlined in Table 1. An empyema is a severe form of CPE defined by the presence of pus in the pleural space. Some would suggest that an empyema may also be defined with a positive gram stain or culture; however, we reserve the true definition of empyema as the presence of purulent fluid (2). Empyema necessitans is a complication of poorly controlled empyema resulting in the infection eroding through the parietal pleura into the soft tissue and ultimately the skin.

\section{Pathophysiology}

Infection of the pleural space develops when a pathogenic organism seeds this area. While pneumonia is the leading cause of empyema, it can occur from direct inoculation (e.g., trauma), other surrounding sources (e.g., esophageal perforation, mediastinitis, subdiaphragmatic abscess), or bacterial seeding from preexisting effusion (3). In this review, we will focus primarily on the treatment of CPE/ empyema as they are the most common community acquired or nosocomial pleural infections acquired by critically ill patients $(4,5)$.
Parapneumonic effusions are categorized into three loosely defined stages: (I) simple or uncomplicated parapneumonic/exudative (stage I); (II) CPE/empyema/ fibrinopurulent (stage II); and (III) organizing (stage III) (6). These stages exist along a continuum of an evolving process. An uncomplicated parapneumonic effusion refers to freeflowing effusions that are sterile. On pleural ultrasound, these effusions appear anechoic and lack complexity (7). A CPE refers to an effusion that has been infected with bacteria or other micro-organisms with a pleural fluid analysis demonstrating intense pleural space inflammation and/or positive gram stain. Pleural ultrasound will typically show septations demonstrating complexity in the pleural space (7). An empyema refers to a collection of pus. Pleural ultrasound for empyema may show a homogenously complex pleural effusion or complex septated (7) (Figure 1A,1B).

The pathogenesis of a stage I uncomplicated parapneumonic effusion results from capillary leak mechanisms resulting in the movement of fluid into the pleural space. With progression to stage II, direct bacterial invasion into the pleural space enhancing the formation of 
septae and increased pleural fluid viscosity. During stage III, progressive fibrin deposition and adhesions from on the visceral pleura surface and pleural space which may lead to a mature fibroelastic membrane which will impede the lung from full re-expansion with fluid evacuation.

\section{Clinical presentation}

The clinical presentation of a pleural infection is often hard to distinguish in patients who have a lower respiratory tract infection. However, a few features may increase the probability that a parapneumonic effusion has developed. These findings include the following: (I) pleurisy; (II) lack of improvement or clinically worsening despite appropriate antimicrobial coverage; and (III) radiographic studies that may demonstrate an increasing effusion. All patients with pneumonia should be promptly evaluated for the presence of a parapneumonic effusion, sampled, drained, and submitted for proper pleural fluid analysis and microbiologic studies that are properly inoculated into aerobic and anaerobic blood culture bottles.

\section{Diagnosis}

The diagnosis is made by thoracentesis. Although $90 \%$ are simple and do not require drainage, early identification and treatment is vital to prevent further progression and complications (8). CPE is diagnosed by the pleural fluid analysis, while empyema occurs when the presence of purulence is noted on fluid appearance. All patients with pneumonia with an effusion should be evaluated for parapneumonic effusion. Table 1 summarizes the pleural fluid characteristics of uncomplicated parapneumonic effusion, CPE, and empyema.

The diagnosis of pleural infection can be a challenging task in the ICU setting. The portable chest radiograph (CXR) is the most commonly utilized imaging study to evaluate pleural effusions among critically ill patients. CXR findings are nonspecific and needs $175-525 \mathrm{~mL}$ of fluid accumulation before distinguishing the presence of a pleural effusion (9). Even when multiple $\mathrm{X}$-ray views are available, a plain radiograph can miss up to $10 \%$ of patients with pleural infections (10).

Thoracic ultrasound (TUS) has become ubiquitous in many ICUs and has the unique capability to identify a pleural effusion. In turn, this can aid with prediction of $\mathrm{CPE}$ and establish prognosis $(7,11)$. TUS can facilitate timely administration of help in initiating early therapy, such as intrapleural fibrinolytics (12-14) (Figure 1A,1B). While computed tomography (CT) can diagnose underlying pneumonia, it is less useful in characterizing septations and other pleural space pathology or help to plan for safe entry into the pleural space. The transportation of unstable, critically ill patients may not be justifiable for the information obtained. CT scan has a role in patients who are not responding to therapy to identify alternate diagnosis or loculated pleural space not seen by TUS, such as fluid accumulation posterior to the scapulae or a mediastinal pocket.

\section{Management}

The principle of management of the infected pleural space is governed by early antibiotics and early evacuation of pleural fluid in the setting of a CPE and/or empyema.

\section{Antimicrobial}

Typically, empyema mimics the underlying pneumonia. Community-acquired infections are generally caused by streptococcus and staphylococcus species (15). In nosocomial infections, MRSA and gram-negative bacteria should be considered for initial antimicrobial therapy. The identification of causative organisms from blood, pleural fluid, and pleural biopsy occurs in $10 \%, 20 \%, 45 \%$ of cases, respectively (16). In up to $76 \%$ of cases, anaerobes may be present but not isolated by standard means $(17,18)$. Therefore, empiric antibiotics should not only aim at covering typical organisms based on local antibiograms but also target anaerobic bacteria (19-22). Most antibiotics for pneumonia penetrate well into the pleural space. However, the acidic environment inactivates aminoglycosides and should be avoided (23). Table 2 summarizes the most common organisms in empyema.

The duration of antibiotic therapy needs to be individualized. Antibiotic therapy should be continued until there is both clinical and radiographical improvement. Therapy may need to be prolonged even after adequate drainage, and a course of 4-6 weeks is recommended (24).

\section{Tube drainage}

The goal of tube drainage is to resolve sepsis and prevent lung entrapment and long-term consequences of fibrothorax or trapped lung. Therefore, early control of pleural infection is vital. Treatment may begin with antibiotics, but ultimately rapid pleural drainage is necessary to prevent progression to the fibrosing and organizing stage of an 
Table 2 Common bacteria organisms that cause complex parapneumonic effusion or empyema

\author{
Common organisms found in complex parapneumonic effusions/empyema \\ Gram positives \\ Streptococcus pneumoniae \\ Streptococcus pyogenes \\ Staphylococcus spp. \\ Gram negatives \\ Klebsiella pneumoniae \\ Enterobacteriaceae spp. \\ Pseudomonas aeruginosa \\ Anaerobes \\ Fusobacterium nucleatum \\ Streptococcus milleri group (intermedius, constellatus, mitis) \\ Prevotella spp. \\ Bacteroides spp. \\ Peptostreptococcus spp.
}

The most common community-acquired pathogens are Streptococcus pneumoniae. The most common healthcare-associated pathogens are MRSA and gram-negative bacteria. Up to $76 \%$ of anaerobes are not present on culture but can be found on genetic sequencing.

empyema.

Although there seems to be no debate among providers for the necessity of drainage, the ideal size of the chest tube remains in contention. Some experts maintain that small-bore catheter may be inadequate when loculation and frank purulence is present (25). However, this has not been demonstrated by randomized control trials. Table 3 summarizes the failure rate of pleural drainage and the chest tube bore size placed in numerous studies. Smallbore chest tubes $(\leq 14 \mathrm{Fr})$ improve patient comfort and avoid complications associated with large-bore chest tubes while still having similar success rates $(1,27,37)$. Placement by Seldinger technique under ultrasound (US) allows for accurate insertion of the chest tube into the dominant pocket of a loculated effusion.

Blunt dissection insertion technique still has some advantages. At times, especially in patients with thick chest walls, it may be challenging to pass the introducer needle into the pleural space. Seldinger technique should ideally be performed with US localization in the interest of patient safety (38). When US availability is limited, and imaging is inadequate for clear guidance, tactile feedback with physical guidance of the pleural tube along the lung tissue may be substituted. Figure 2 shows the confirmation of the guidewire in the pleural space during insertion of a chest tube using Seldinger technique.

\section{Intrapleural fibrinolytic therapy (IPFT)}

IPFT has been part of the treatment algorithm for pleural empyema for more than half a century. It was first described by Tillett in 1949. Tillett and colleagues described the combination of streptokinase and streptococcal deoxyribonuclease to decrease the pleural fluid viscosity and improved drainage of patients with empyema (39). Since then, there have been numerous smaller randomized control trials that have resulted in promising data, which have reduced the requirement for surgical intervention (33-36).

The Multicenter Intrapleural Sepsis Trial (MIST) was unable to find any difference in drainage failure between using fibrinolytic alone versus placebo (19). The second intrapleural sepsis trial (MIST2) added dornase alfa (DNAse) to fibrinolytics (39). The authors compared alteplase (tPA) alone, DNAse alone, tPA and DNAse, and placebo. They recruited 210 subjects, the majority of whom had small-bore chest tubes $(<15 \mathrm{Fr})$. The primary outcome of MIST-2 was based on radiographic change on CXR. The results of the study found no difference 
Table 3 Summary of major trials with outcomes and chest tube size

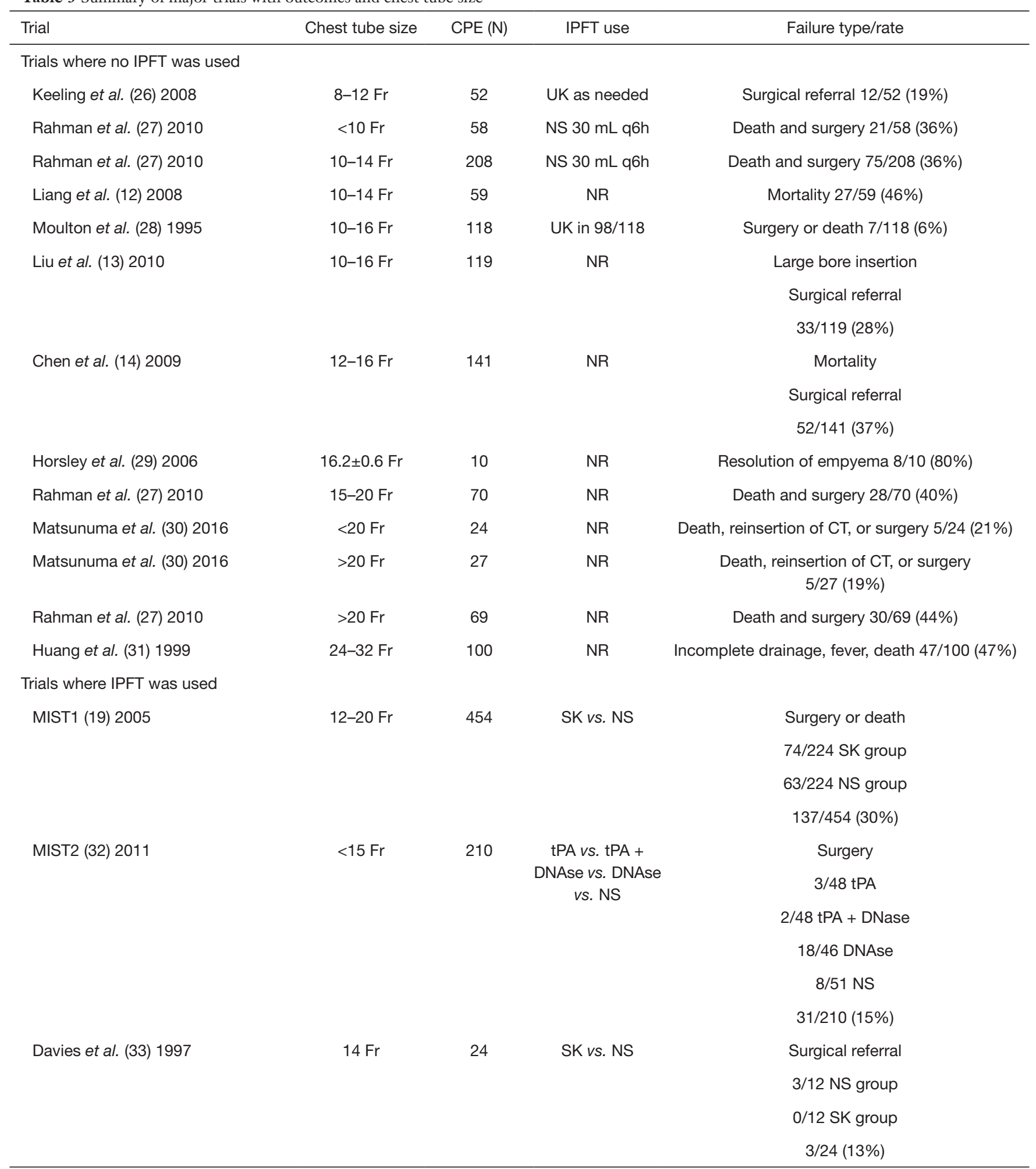

Table 3 (continued) 
Table 3 (continued)

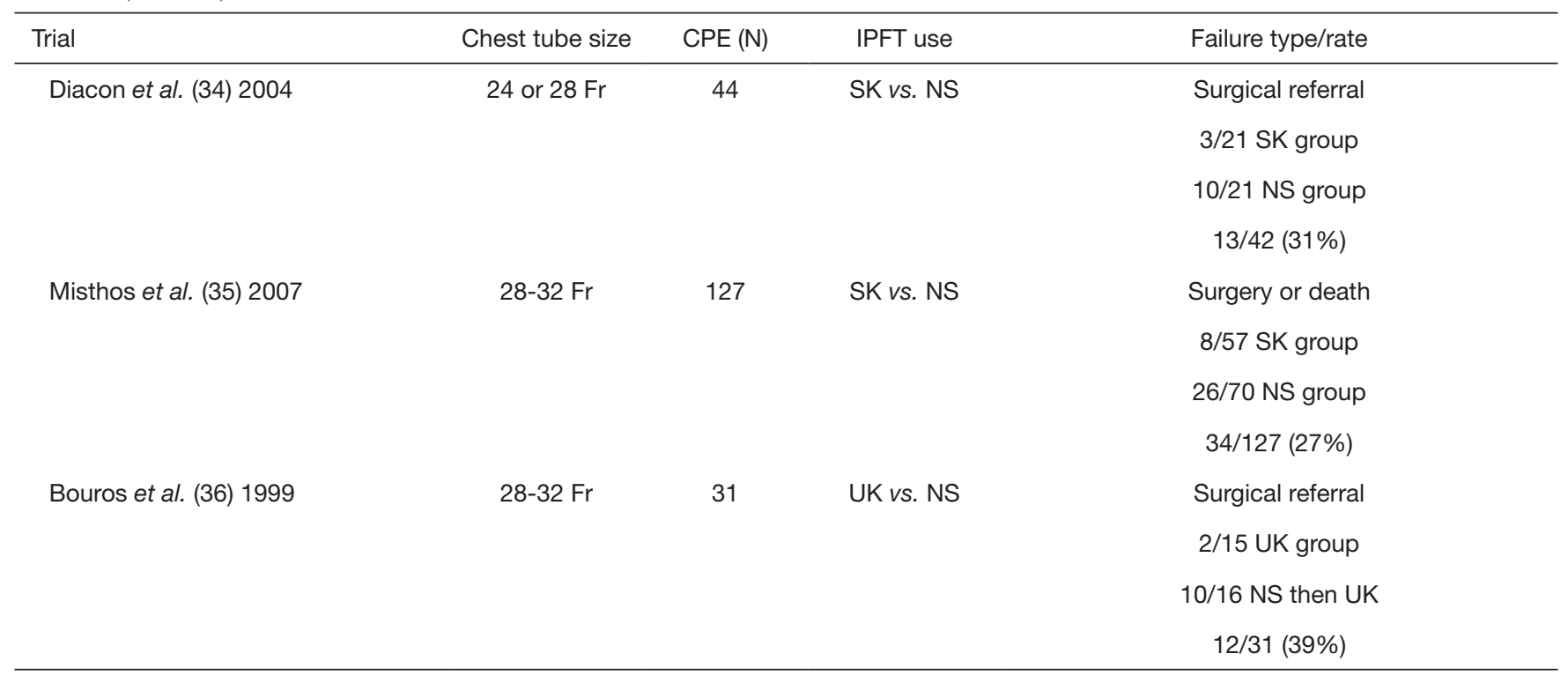

CPE, complicated parapneumonic effusion; IPFT, intrapleural fibrinolytic therapy; Fr, French; UK, urokinase; NS, 0.9\% saline; NR, not reported; CT, chest tube; SK, streptokinase; tPA, alteplase; DNAse, dornase alfa.

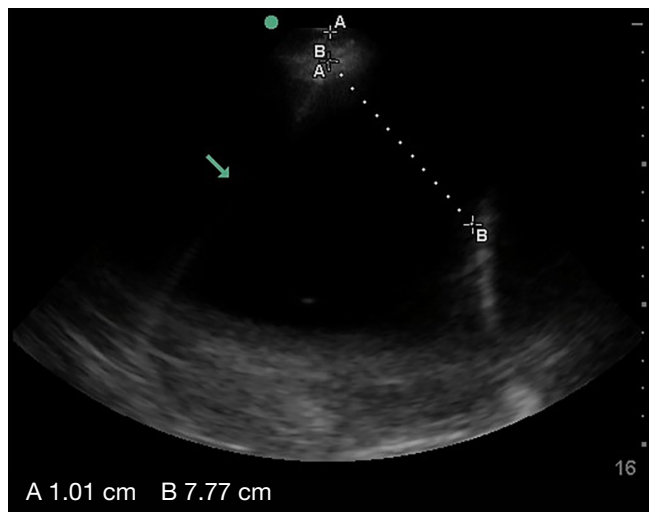

Figure 2 Ultrasound image of confirmed guidewire placement in the pleural space. The green arrow points towards the echogenic wire in the anechoic pleural fluid.

in radiographic change when comparing placebo to tPA or DNAse alone $(-17.2 \%$ vs. $-17.2 \%$ vs. $14.7 \% ; \mathrm{P}=0.55$, $\mathrm{P}=0.14)$. However, when tPA and DNAse were combined, there was a significant decrease in radiographic findings (-29.5\% vs. $-17.2 \% ; \mathrm{P}=0.005)$, surgical referrals $(4.1 \%$ vs. $16 \%$; OR $0.17 ; \mathrm{P}=0.03)$, and hospital length of stay $(11.8 \pm 9.4$ vs. $24.8 \pm 56.1$ days; $\mathrm{P}<0.001)$. Three open-label trials after MIST2 have confirmed the effectiveness of tPA/DNAse combination (40-42). A recent Cochrane review also showed that IPFT reduces surgical referral but does not reduce mortality (43).

MIST2 used a combination of $10 \mathrm{mg}$ of tPA and $5 \mathrm{mg}$ of DNAse instilled into the pleural space 2 hours apart every 12 hours for three days (32). This practice can sometimes be cumbersome and resource-intensive. Majid and colleagues showed that the simultaneous administration of tPA and DNAse did not change the clinical outcome (41). Mehta and colleagues showed that once a day administration of $10 \mathrm{mg}$ of tPA and $5 \mathrm{mg}$ of DNase was adequate for therapy (42). The findings of these open-label trials are summarized in Table 4. The ideal dosing and schedule for tPA/DNAse have yet to be determined.

The main complication of IPFT is intrapleural bleeding and has a reported incidence of $1.8-12 \%(40-42,45)$. tPA is the primary risk factor for hemorrhage. No ideal dose of tPA or DNAse has been determined. The ADAPT trial showed that decreasing tPA from $10 \mathrm{mg}$ to $5 \mathrm{mg}$ in combination with DNAse did not reduce efficacy (44). The ongoing ADAPT-2 trial may further improve the safety of this treatment by supporting for the additional reduction in tPA dosing. Alternatively, the use of urokinase has been shown to have similar efficacy but with significantly less intrapleural hemorrhage (46). 
Table 4 Summary of major open label IPFT trials since MIST2. tPA, alteplase; DNAse, dornase alfa

\begin{tabular}{|c|c|c|c|c|}
\hline Study & Intervention & $\mathrm{N}$ & Need for surgery (\%) & Mortality (\%) \\
\hline Piccolo et al. (40) 2014 & $10 \mathrm{mg}$ tPA and $5 \mathrm{mg}$ DNAse 2-hour apart q12 hours & 107 & $8(7.5)$ & $3(2.8)$ \\
\hline Majid et al. (41) 2016 & Concurrent $10 \mathrm{mg}$ tPA with $5 \mathrm{mg}$ DNAse q12 hours & 73 & $7(9.6)$ & $2(2.7)$ \\
\hline ADAPT trial (44) 2016 & Reduced $5 \mathrm{mg}$ tPA with $5 \mathrm{mg}$ DNAse q12 hours & 61 & $3(4.9)$ & $1(1.6)$ \\
\hline
\end{tabular}

\section{Novel techniques}

A possible alternative to IPFT is pleural irrigation. A pilot trial of 47 patients compared either flushing $250 \mathrm{~mL}$ of $0.9 \%$ saline into the pleural space by gravity through a small-bore chest tube or standard therapy. The use of pleural saline irrigation reduced surgical referrals with no significant adverse effects (47).

\section{Additional drainage tubes}

When drainage is inadequate from a single chest tube, which may occur with a multiloculated effusion despite IPFT, we recommend that additional catheters be placed under image guidance. CT imaging is preferred but can be done under ultrasound in the hand of experienced providers. Additional IPFT through a second or third drain may provide clearance and avoid surgery. However, the efficacy and safety of this approach remain unclear.

\section{Assessment for improvement}

Assessing the efficacy of therapy with drainage volume alone may be falsely reassuring. Traditionally, a CT scan is the best modality for radiographic improvement as it allows for evaluation of the underlying parenchyma and visualization of additional locules (48). However, transporting a critically ill patient has risks (49). TUS can help determine if the fluid around the catheter is adequately drained and can be performed rapidly at the bedside by the clinician.

\section{Medical thoracoscopy (MT)}

MT is a minimally invasive procedure that has been around for more than a century. It may be an alternative to surgical decortication. MT has been shown to be safe and effective in the treatment of pleural infections (50-52). MT can be performed by either an interventional pulmonologist or a thoracic surgeon and be conducted with local anesthesia and moderate sedation. A recent small trial comparing IPFT versus MT, showing that MT has the potential to reduce hospital length of stay (53). Although there remains a lack of data, MT should be considered as an alternative to surgery when conservative measures fail.

\section{Surgical options}

The perioperative mortality rate for a surgical decortication procedure for pleural infection is reported to be $3.1 \%$, with significant postoperative morbidity of $30.2 \%$. Open thoracotomy carried higher perioperative mortality and postoperative morbidity when compared to video-assisted thoracoscopic surgeries (VATS) (mortality 2.8\% vs. 3.7\%; morbidity $13.9 \%$ vs. $18.0 \%$ ). Patients of older age, reduced renal function, elevated BMI, COPD, and decreased functional status were all predictors of mortality and morbidity. Sicker patients with higher American Society of Anesthesiologist (ASA) physiological status classes (ASA I/II $v s$. ASA III/IV/V/VI) were two times as likely to die [OR 2.07 (1.66-2.60), $\mathrm{P}<0.001]$ and ten times more likely to have significant morbidity [OR 10.15 (1.41-73.12), $\mathrm{P}=0.0215]$ (54). Therefore, all other options should be exhausted before resorting to surgery.

\section{Summary}

Early diagnosis of pneumonia and the use of antibiotics has decreased the overall incidence of pleural infections and pleural space complications. However, epidemiological studies suggest that the rates of complicated pleural infections may be rising again (5). Undoubtedly, a subset of these patients will present to the ICU. Early diagnosis and proper antibiotic selection are still the cornerstones of initial therapy. TUS evaluation should be performed on all patients with pneumonia to rule out $\mathrm{CPE}$. Pleural sampling should be used for diagnosis. Pleural drainage is needed for all CPE/empyema. The use of small-bore chest tubes has a similar failure rate compared to large-bore chest tubes and is more comfortable for patients. IPFT should be started 


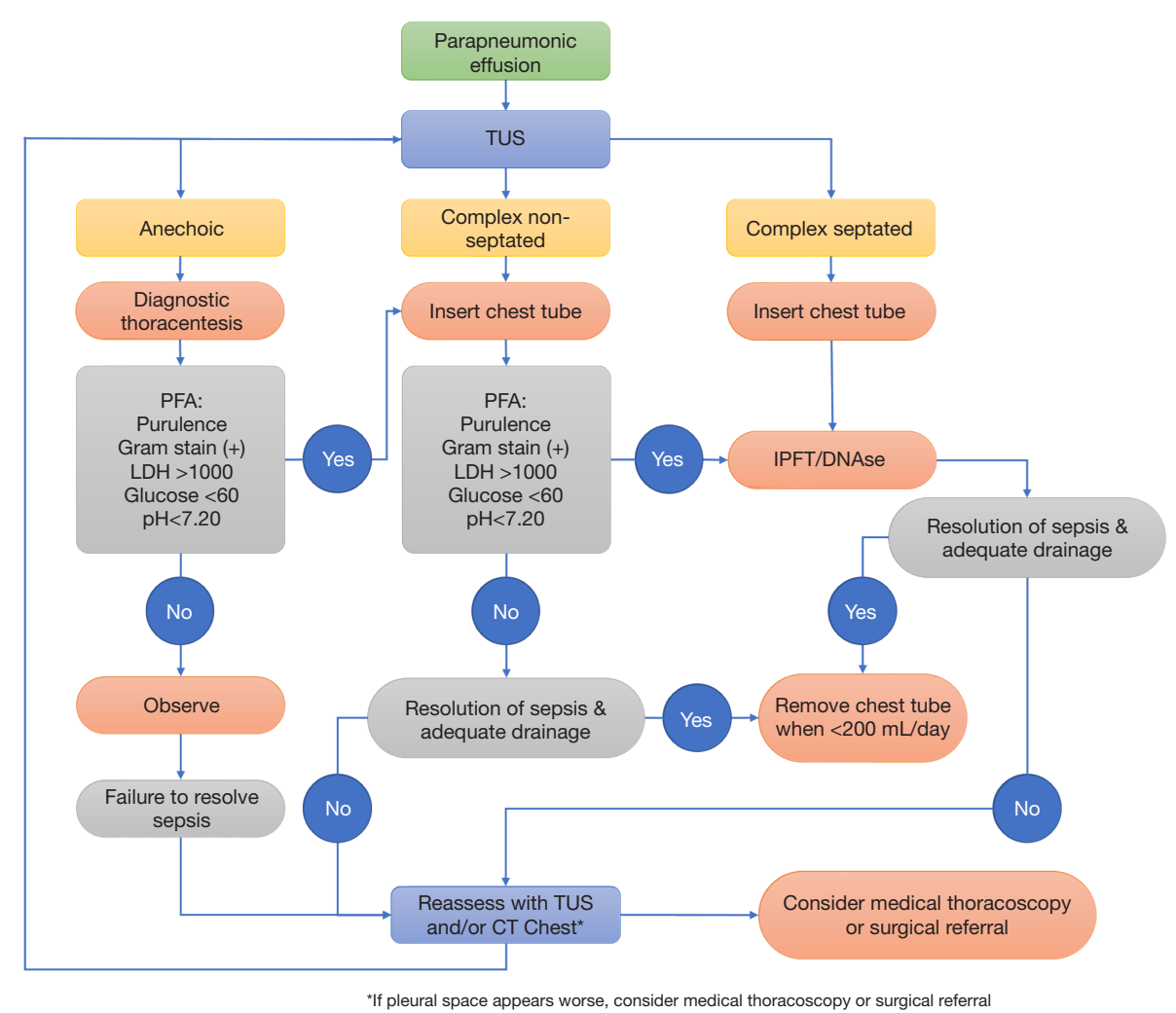

Figure 3 Algorithm for evaluation and management of parapneumonic effusion. TUS, thoracic ultrasound; PFA, pleural fluid analysis; LDH, lactic acid dehydrogenase; IPFT, intrapleural fibrinolytic therapy; DNAse, dornase alfa; CT, computed tomography.

early to prevent surgery. Some emerging data show that surgery should be performed early (55). However, this is not always feasible in the critically ill patient. MT be a viable alternative that can be performed at the bedside and allow for better drainage.

We recommend early empiric antibiotics and anaerobic coverage based on local antibiograms and de-escalating antibiotics once the organism has been identified or resistant organisms have been excluded. We also recommend the initial use of small-bore pleural drains (14 Fr) inserted under direct ultrasound guidance in combination with IPFT with $10 \mathrm{mg}$ of tPA and $5 \mathrm{mg}$ of DNAse every 12 hours for the treatment of CPE and pleural empyema (Figure 3).

\section{Hemothorax}

\section{Introduction}

The leading causes of hemothorax are blunt or penetrating thoracic trauma, and therefore the majority of cases are managed in the surgical ICU. The diagnosis of hemothorax is a surgical emergency, where there may be a need for immediate surgical exploration for the management of hemothorax (56). Rarely, a hemothorax can occur spontaneously (Table 5) $(57,58)$.

\section{Definition}

Hemothorax is a collection of blood in the pleural space and is defined by a pleural fluid hematocrit $>50 \%$ of the serum hematocrit. However, blood in pleural fluid gets diluted over 3-4 days by the process of osmosis, which may inadvertently lower the hematocrit below $50 \%$. Therefore, hemothorax is still a possibility in the right clinical setting even when the pleural hematocrit may be $<50 \%$ of the serum hematocrit (59).

\section{Pathophysiology}

Hemothorax can originate from intrathoracic vasculature, such as intercostal vessels, internal mammary vessels, 
Table 5 Common causes of hemothorax

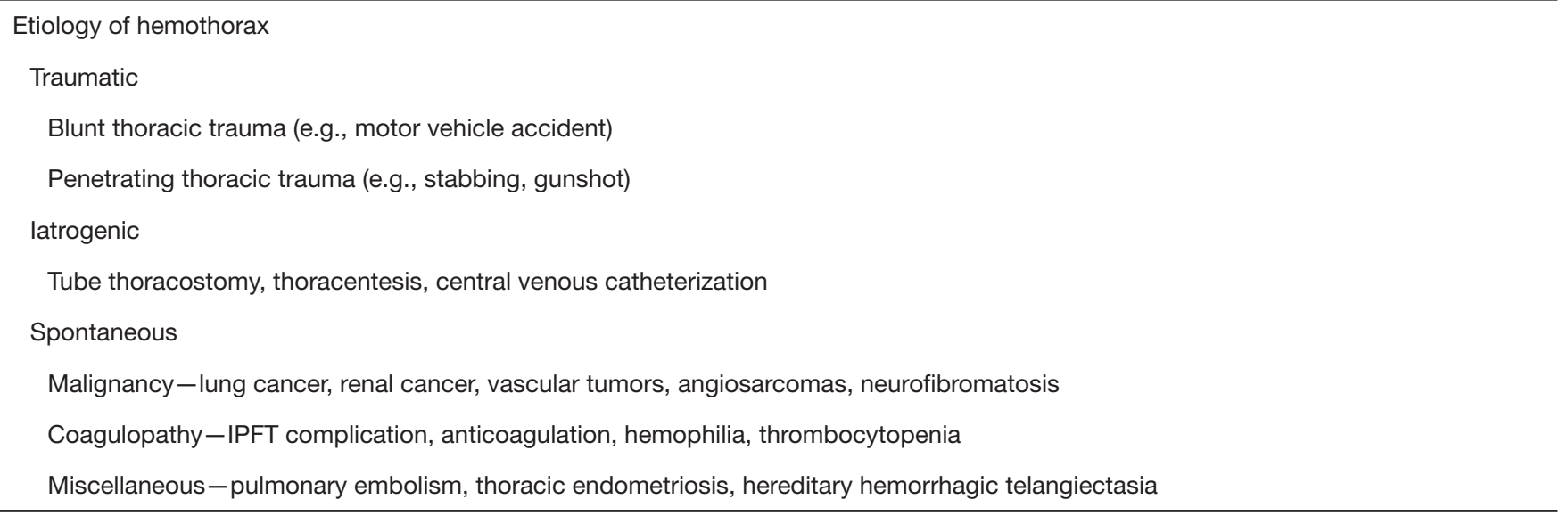

IPFT, intrapleural fibrinolytic therapy.

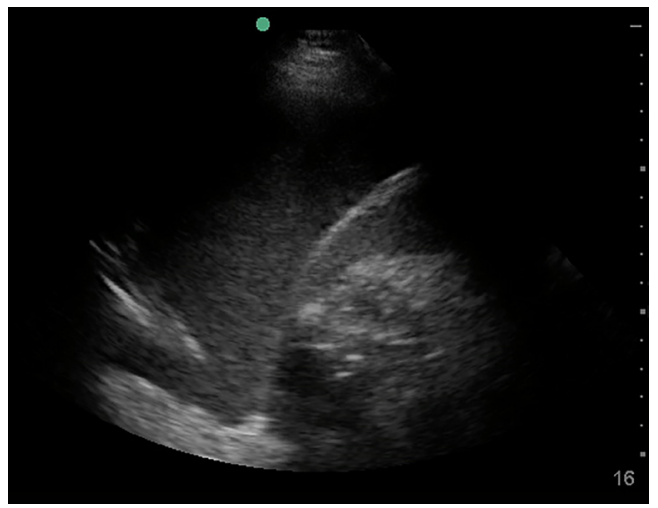

Figure 4 Hematocrit sign found on ultrasound in a patient with a hemothorax. The echogenicity of the fluid increases with depth.

aorta, and pulmonary vasculature. It can also come from extrathoracic origins, such as intrabdominal vessels. Once active bleeding stops, the fibrinolytic system attempts to lyse the clot. However, in cases where the fibrinolysis is incomplete, the clot can organize within the pleural space, resulting in the formation of pleural peel and lead to the development of trapped lung and/or fibrothorax (Figure 3).

\section{Clinical presentation}

Clinical presentation depends upon the rapidity of extravasation of the blood and underlying etiology. Massive hemothorax is defined as the accumulation of $>1.5 \mathrm{~L}$ of the blood over 24 hours, which can have severe effects on the cardiopulmonary system such as hypotension, acute respiratory failure, and cardiopulmonary arrest.

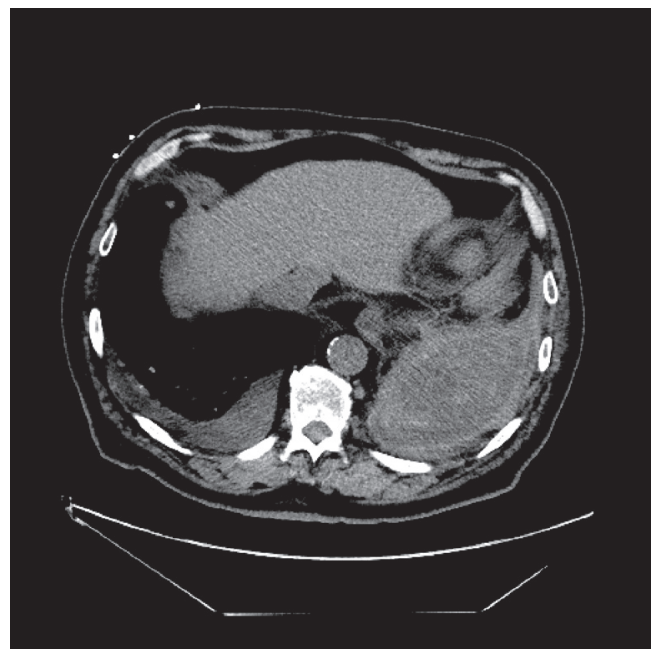

Figure 5 Thickened pleura from retained hemothorax.

\section{Diagnosis}

Early recognition and treatment of hemothorax can be lifesaving in patients with a hemothorax. Hemothorax should be considered in all patients with thoracic trauma. TUS is a quick, inexpensive, and sensitive screening tool for the detection of hemothorax during an initial trauma evaluation. Multiple studies have shown that TUS has a higher sensitivity than chest $\mathrm{X}$-ray in detecting hemothorax in patients with blunt trauma (Figure 4) $(60,61)$. Contrastenhanced chest CT should be performed after the initial screening to identify the source of bleeding, which may also reveal an underlying etiology and the presence of injuries to vital organs (Figure 5) (62). 


\section{Management}

Small hemothorax, in the absence of hemodynamical instability, can be managed conservatively with pain control and serial monitoring of the hemothorax size. Hemodynamically unstable patients should be aggressively resuscitated with blood transfusion and intravenous fluid (63). Tube thoracostomy is the mainstay of the management of moderate to large hemothorax. There is a theoretical concern of tube occlusion while using small-bore chest tubes. However, multiple studies have shown similar results between small-bore (14 French) and large bore (>28 French) chest tubes (64). Tube size is chosen based on personal preference. Regardless, tube occlusion and output should be closely monitored in patients with hemothorax. Surgical exploration via VATS or anterolateral thoracotomy may be required in patients who continue to have a large amount of active bleeding, defined as $>1.5 \mathrm{~L}$ of blood in the first 24 hours, $>200 \mathrm{~mL}$ per hour for $2-3$ consecutive hours, or presence of vital organ injuries (65).

Survivors of hemothorax can develop a retained hemothorax (clotted blood occupying $>1 / 3^{\text {rd }}$ of hemithorax) if the hemothorax is not properly drained in a timely fashion. This may result in complications such as empyema, trapped lung, or even fibrothorax (65-67). Therefore, a retained hemothorax should be evacuated. Recent data suggest that IPFT may be equally effective in evacuating retained hemothorax (68). If IPFT fails, then surgical evacuation may be required (69).

\section{Summary}

Hemothorax generally occurs in the setting of trauma and is typically managed in the surgical ICU. Small hemothoraces can be managed conservatively, while larger ones will require drainage to prevent progression to fibrothorax. Although many experts still advocate for large-bore chest tubes, small-bore chest tubes are equally effective. IPFT therapy can be considered if there is inadequate drainage, but surgical evacuation is the definitive therapy for a retained hemothorax.

We recommend placement of small-bore chest tubes initially and upsizing to a large bore if there is inadequate drainage. Retained hemothorax can be managed by IPFT therapy in the critically ill patient, but if active bleeding is suspected, surgical evaluation is still the preferred method.

\section{Pneumothorax}

Pneumothorax can be classified into spontaneous or iatrogenic. Pneumothorax can be complicated by tension pneumothorax, hemopneumothorax, pyopneumothorax, and open pneumothorax. Pneumothorax is an independent predictor of mortality in patients on mechanical ventilation (70). Pneumothorax from barotrauma, concurrent pneumothorax with septic shock, and those who progress to tension pneumothorax were all significantly associated with increased mortality in the ICU (71). In this review, we will focus on the most common causes of pneumothorax in the ICU, including iatrogenic, and pneumothorax resulting from barotrauma/volutrauma (Table 6).

\section{Definition}

Pneumothorax is the accumulation of extra-alveolar air in the pleural space. There are six ways in which air can leak into the pleural space: (I) rupture or injury of the visceral pleura that allows for air to escape from the alveoli into the pleural space (e.g., barotrauma or volume trauma); (II) entry of air from the atmosphere due to chest trauma or iatrogenic needle injury; (III) rupture of adjacent hollow viscous (e.g., Boerhaave's syndrome); (IV) transdiaphragmatic spread of air from the abdomen, (V) excess production from gas-forming organisms in the pleural space; and (VI) secondary rupture of the mediastinal pleura from a preexisting pneumomediastinum which is believed is the most common pathogenic mechanism in secondary spontaneous pneumothorax (72).

\section{Clinical presentation}

Pneumothorax can be challenging to recognize in the critically ill patient. Acute onset of dyspnea or chest pain, tachycardia, hypotension, pulsus paradoxus, contralateral tracheal deviation, and sudden increase in peak and plateau pressure in a mechanical ventilated patient can point at a diagnosis. Physical exams and other clinical signs are unreliable and nonspecific. Confirmation by imaging is still necessary to make the diagnosis (73).

\section{Diagnosis}

CXR is still the most commonly used tool to diagnose a pneumothorax. An anteroposterior portable CXR in a 
Table 6 Etiologies of pneumothoraces in patients in the intensive care unit

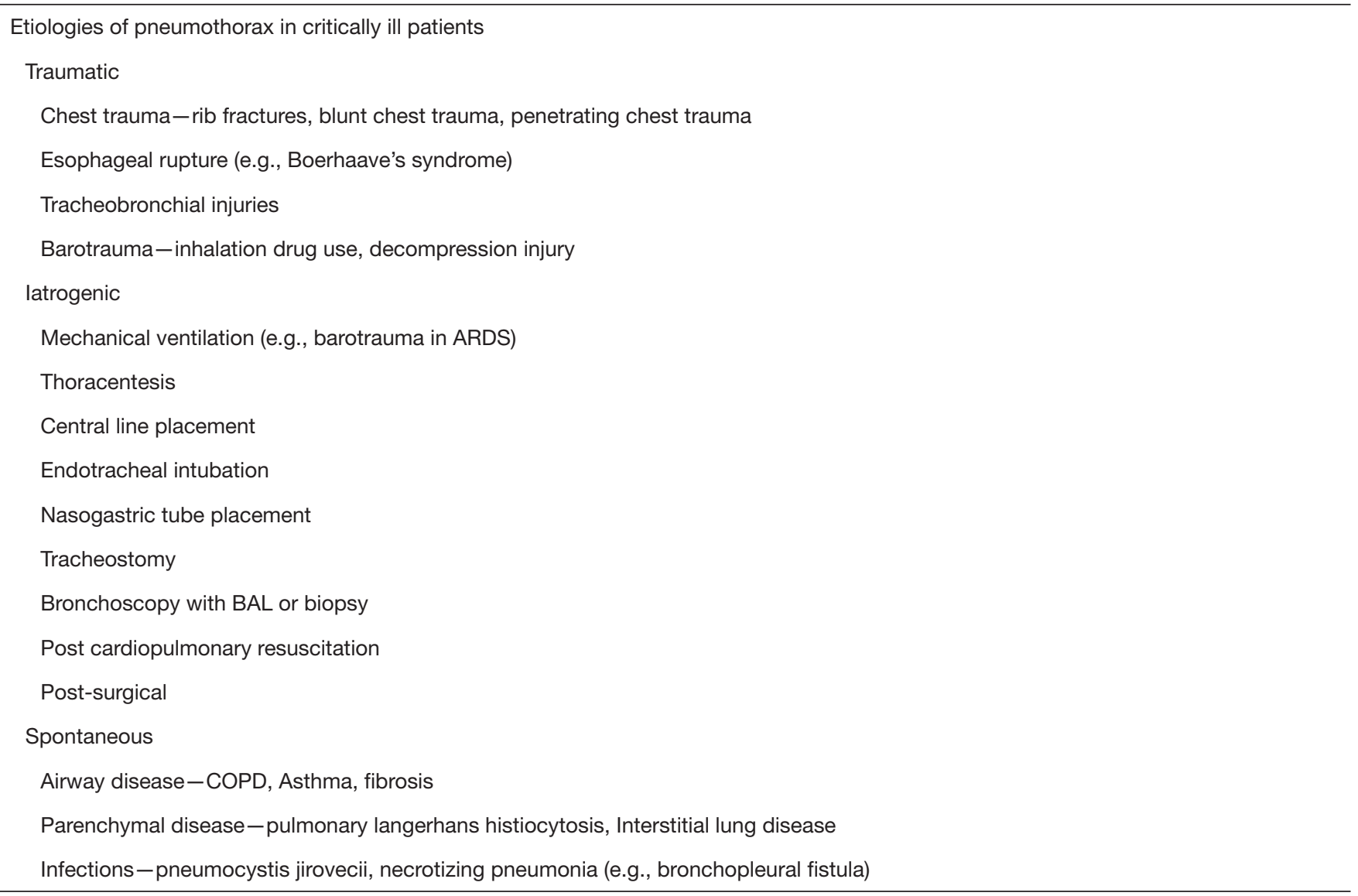

ARDS, acute respiratory distress syndrome; COPD, chronic obstructive pulmonary disease; BAL, bronchoalveolar lavage.

supine patient is unreliable for diagnosing pneumothorax in the ICU $(9,74)$. Increasing evidence suggests that thoracic US, in a set of experienced hands, can be accurate in diagnosing a pneumothorax. The absence of pleural sliding next to the presence of pleural sliding, known as lung point sign, is $100 \%$ specific for pneumothorax (75). The diagnostic accuracy of portable CXR was only $46 \%$ compared to $87 \%$ with US (74).

Chest CT remains the gold standard for diagnosing and evaluating the size of a pneumothorax. However, this requires patient transport and delays the diagnosis, which may be unacceptable in a hemodynamically unstable patient.

\section{Management}

Tension pneumothorax is a medical emergency, and delay in therapy can lead to respiratory and hemodynamic decline leading to death. This is especially true for patients on mechanical ventilation (76). Pneumothorax should be suspected when there is sudden worsening in oxygenation, increased tachycardia, tachypnea, or worsening in lung compliance (77). When therapy cannot be delayed for confirmation, immediate needle decompression should be performed with a large-bore (14- to 16-gauge) anigocatheter attached to a syringe filled with fluid between the $4^{\text {th }}$ and $5^{\text {th }}$ intercostal space at the mid- or anterior-axillary line $(78,79)$. Chest tube can be initially considered, if the provider is experienced and if materials are immediately available. If needle decompression is used, a chest tube should then be inserted once the patient has been stabilized to prevent further decompensation.

A small-bore chest tube is comparable to a large-bore chest tube when treating pneumothorax in mechanically ventilated patients $(71,80)$. If a small-bore catheter fails to drain the air adequately, then a large-bore chest tube should be placed. Insufficient evacuation of air from the pleural space may be indicated by worsening subcutaneous emphysema. This finding can be identified by regular 


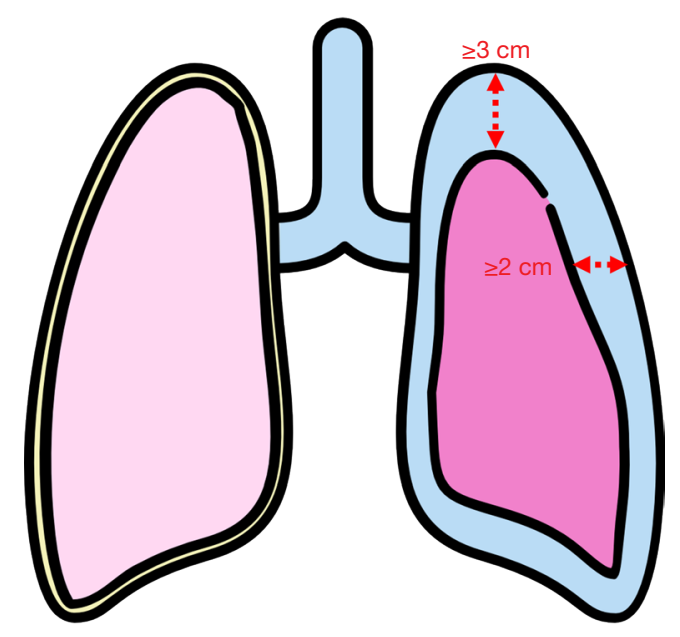

Figure 6 Pneumothorax is classified as large on a frontal chest $\mathrm{X}$-ray if the distance from the margin of the lung to the chest wall is $2 \mathrm{~cm}$ from the chest wall at the level of hilum or $3 \mathrm{~cm}$ from the apex of the lung. On CT scan a large pneumothorax occupies $>20 \%$ of the ipsilateral hemithorax.

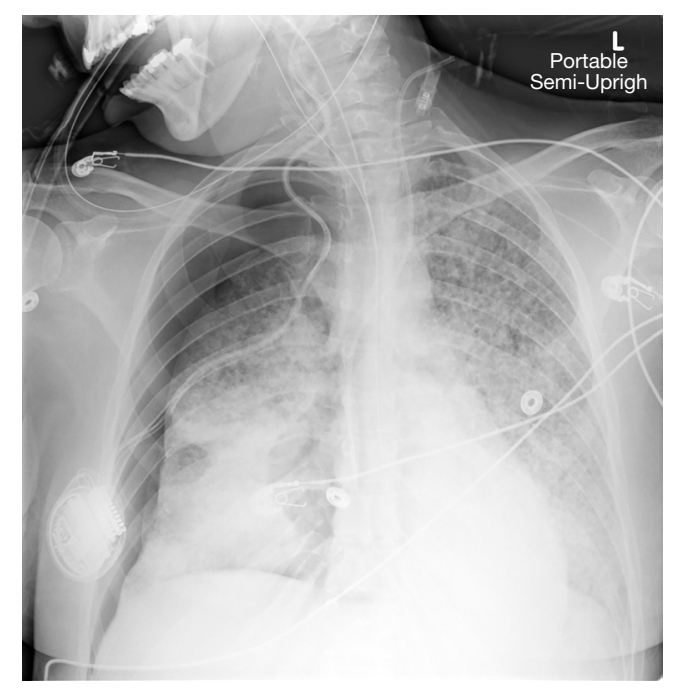

Figure 7 Large right sided pneumothorax on frontal portal chest $\mathrm{X}$-ray in a patient on mechanical ventilation occurring after the patient had a chest wall biopsy.

palpation around the chest tube insertion site to identify expanding crepitus. Blunt dissection technique or CT guided placement of chest tube should be performed in the presence of large bullae.

The application of negative intrathoracic suction via the chest tube has been advocated for the therapy for pneumothorax in order to reduce the amount of air and allow for quick lung re-expansion, by reducing the pleural pressure back to its normal resting state. Suction with a high-volume, low-pressure system is generally desired. Such a system provides for the removal of large air leaks but not cause an excessive drop in pleural pressure. Optimal suction should be conducted with pressures of -10 to $-20 \mathrm{cmH}_{2} \mathrm{O}$ $(81,82)$.

In the non-mechanically ventilated patient, management should depend on how the patient is affected clinically and the pneumothorax size (Figure 6) $(81,83)$. In a patient with a sufficient physiological reserve, it may be reasonable to observe a small iatrogenic pneumothorax. In a study of trauma patients with occult pneumothoraces, there was no difference in outcomes with or without chest tube insertion $(84,85)$.

However, the majority of patients on mechanical ventilation with a small pneumothorax will progress to tension physiology and intervention is recommended (Figure 7) (86,87). If the pneumothorax is not large enough for chest tube placement, then careful monitored with serial $\mathrm{X}$-rays and pleural US should be conducted.

In most cases when the air leak resolves and the lung reexpands, the chest tube can be removed. However, when an air leak persists $>5$ days, which defines a persistent air leak, then more definitive therapy may need to be pursued (88). If patients are on mechanical ventilation, then the liberation from the ventilator should be performed before definitive treatment to close the air leak. Patients with persistent air leaks should have their mean airway pressure and suction pressure minimized to promote air leak closure. If the patient displays possible unexpandable lung physiology, manometry may help in differentiating in the diagnosis of an unstable air leak, which may require more definitive therapies $(89,90)$. Many critically ill patients may not remain a good candidate for a surgical procedure. Therefore, bronchoscopic techniques, especially with more recent refinements, should be considered. Discussion of such procedures is beyond the scope of this review. We recommend the management algorithm shown in Figure 8.

\section{Summary}

The diagnosis of pneumothorax can be challenging on portable CXR. Chest CT is the gold standard for the diagnosis but may not be feasible in the critically ill patient. US is a quick and accurate way of ruling in pneumothorax when lung-point sign is identified. The 


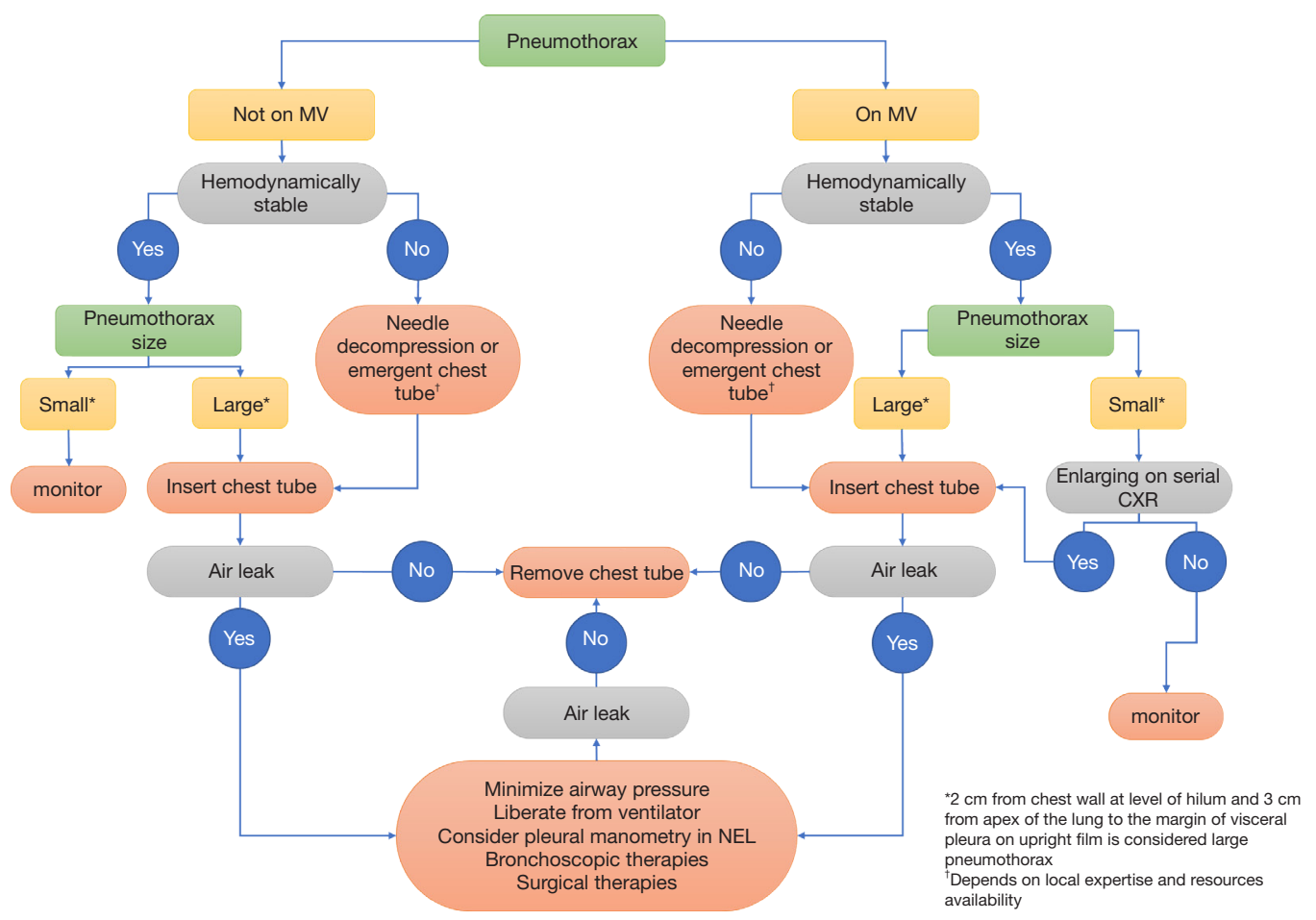

Figure 8 Algorithm for management of pneumothorax in the ICU. MV, mechanical ventilation; NEL, non-expandable lung.

presence of lung sliding does not always mean the absence of a pneumothorax. The cornerstone of therapy is pleural drainage and is especially important when patients are on mechanical ventilation. Conservative management includes optimizing ventilator pressures and applying suction to actively evacuate the air. Once liberated from the ventilator, more definitive therapies can be performed.

We recommend the placement of small-bore chest tubes $(<15 \mathrm{Fr})$ under Seldinger technique for the initial management of a pneumothorax. If a small-bore chest tube is inadequate, then placement of a large-bore chest tube with blunt dissection should be performed. If there is a concern for bullous disease, then CT-guided placement is recommended (Figure 8).

\section{Pleural fluid of extravascular origin (PEEVO)}

PEEVO is a rare type of pleural effusion that does not originate from the pleural vasculature and results from the migration of fluid from an extra-pleural space such as the abdomen, the genitourinary system, the biliary system, or the central nervous system $(91,92)$. PEEVO is a rare cause of pleural effusion in critically ill patients. However, the diagnosis can be very challenging. Often patients with
PEEVO undergo multiple pleural procedures before the diagnosis is made, and therefore, a high index of suspicion is needed in the appropriate clinical context. Table 7 summarizes various causes of PEEVO. Specific details of each cause of PEEVO is beyond the scope of this review (2).

\section{Conclusions}

Pleural disorders can be hard to diagnose in patients in the ICU. CXR may not always be helpful due to the underlying lung pathology. US has revealed itself to be a useful tool for the bedside clinician. Management of disorders such as $\mathrm{CPE}$, hemothorax, and pneumothorax, can require additional expertise. Drainage remains the hallmark therapy for many pleural disorders. Although there is abundant data that shows that small-bore chest tube is comparable to large-bore chest tube in most pleural space disorders, there has yet to be any randomized controlled trial. Intrapleural therapy for CPE/empyema is widely accepted to reduce surgical referral and may help with the clearance of pleural sepsis. As we continually advance the understanding of the physiological processes and improve in diagnostics, there will be further refinement of therapies. 


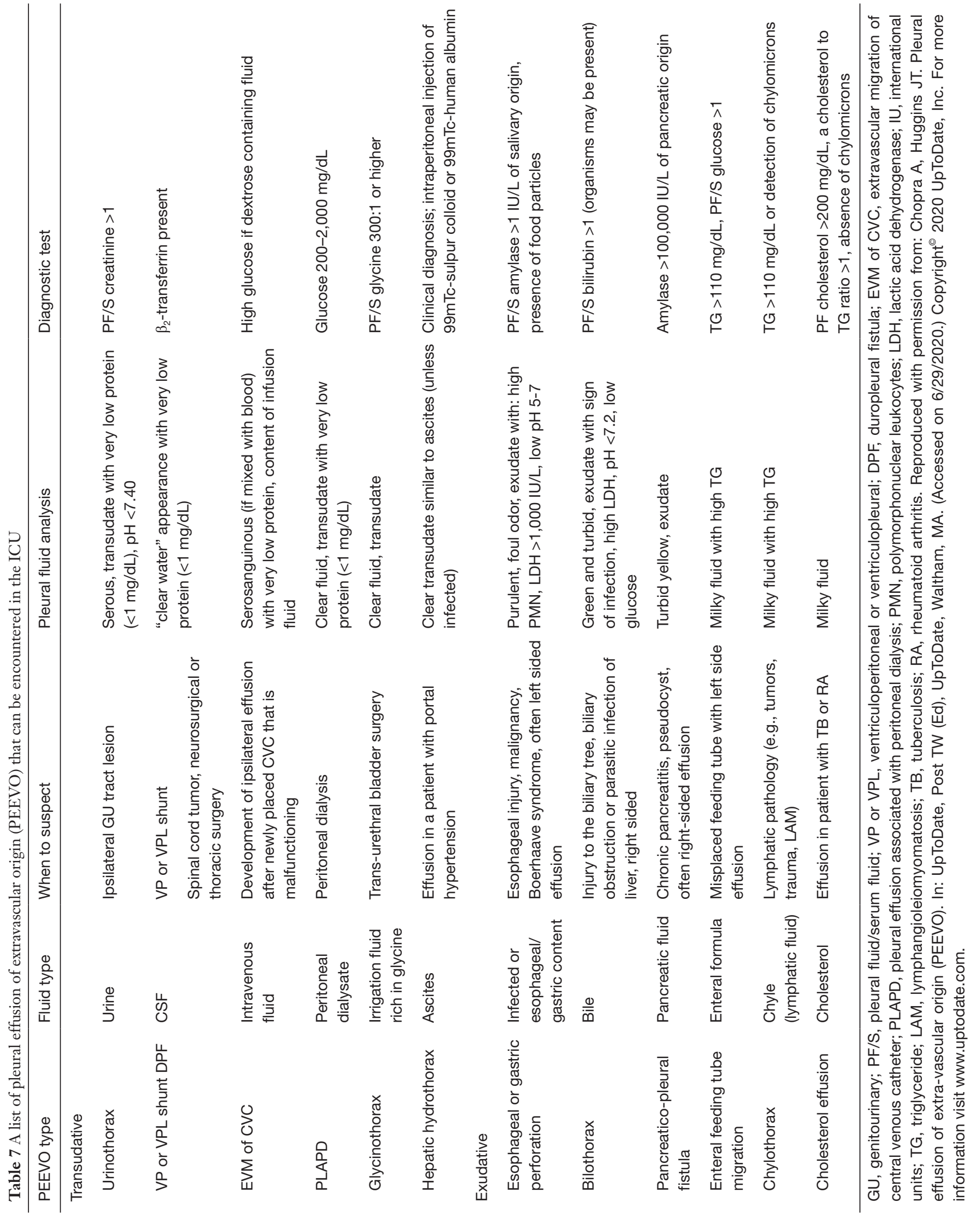




\section{Acknowledgments}

Funding: None.

\section{Footnote}

Provenance and Peer Review: This article was commissioned by the editorial office, Fournal of Thoracic Disease for the series "Interventional Pulmonology in the Intensive Care Unit Environment". The article has undergone external peer review.

Conflicts of Interest: All authors have completed the ICMJE uniform disclosure form (available at: https://dx.doi. org/10.21037/jtd-2021-31). The series "Interventional Pulmonology in the Intensive Care Unit Environment" was commissioned by the editorial office without any funding sponsorship. JK served as the unpaid Guest Editor of the series. JK reports personal fees from Level Ex, personal fees from Medtronic, other from Pinnacle Biologics, personal fees from Biodesix; personal fees from American Medical Forum, and outside the submitted work. The other authors have no conflicts of interest to declare.

Ethical Statement: The authors are accountable for all aspects of the work in ensuring that questions related to the accuracy or integrity of any part of the work are appropriately investigated and resolved.

Open Access Statement: This is an Open Access article distributed in accordance with the Creative Commons Attribution-NonCommercial-NoDerivs 4.0 International License (CC BY-NC-ND 4.0), which permits the noncommercial replication and distribution of the article with the strict proviso that no changes or edits are made and the original work is properly cited (including links to both the formal publication through the relevant DOI and the license). See: https://creativecommons.org/licenses/by-nc-nd/4.0/.

\section{References}

1. Sahn SA. Diagnosis and management of parapneumonic effusions and empyema. Clin Infect Dis 2007;45:1480-6.

2. Sahn SA. The value of pleural fluid analysis. Am J Med Sci 2008;335:7-15.

3. Strange C, Sahn SA. The definitions and epidemiology of pleural space infection. Semin Respir Infect 1999;14:3-8.

4. Antibiotic E, Day A, Andriukaitis V, et al. Healthcare- associated infections acquired in intensive care units. ECDC Annu Epidemiol Rep 2016. Available online: https://www.ecdc.europa.eu/en/healthcare-associatedinfections-acquired-intensive-care-units

5. Grijalva CG, Zhu Y, Nuorti JP, et al. Emergence of parapneumonic empyema in the USA. Thorax 2011;66:663-8.

6. Andrews NC. Management of nontuberculous empyema: a statement of the subcommittee on surgery. Am Rev Respir Dis 1962;85:935.

7. Shkolnik B, Judson MA, Austin A, et al. Diagnostic Accuracy of Thoracic Ultrasonography to Differentiate Transudative From Exudative Pleural Effusion. Chest 2020;158:692-7.

8. Light RW. Parapneumonic effusions and empyema. Proc Am Thorac Soc 2006;3:75-80.

9. Woodring JH. Recognition of pleural effusion on supine radiographs: how much fluid is required? AJR Am J Roentgenol 1984;142:59-64.

10. Brixey AG, Luo Y, Skouras V, et al. The efficacy of chest radiographs in detecting parapneumonic effusions. Respirology 2011;16:1000-4.

11. Svigals PZ, Chopra A, Ravenel JG, et al. The accuracy of pleural ultrasonography in diagnosing complicated parapneumonic pleural effusions. Thorax 2017;72:94-5.

12. Liang SJ, Tu CY, Chen HJ, et al. Application of ultrasound-guided pigtail catheter for drainage of pleural effusions in the ICU. Intensive Care Med 2009;35:350-4.

13. Liu YH, Lin YC, Liang SJ, et al. Ultrasound-guided pigtail catheters for drainage of various pleural diseases. Am J Emerg Med 2010;28:915-21.

14. Chen CH, Chen W, Chen HJ, et al. Transthoracic ultrasonography in predicting the outcome of smallbore catheter drainage in empyemas or complicated parapneumonic effusions. Ultrasound Med Biol 2009;35:1468-74.

15. Marks DJ, Fisk MD, Koo CY, et al. Thoracic empyema: a 12-year study from a UK tertiary cardiothoracic referral centre. PLoS One 2012;7:e30074.

16. Psallidas I, Kanellakis NI, Bhatnagar R, et al. A Pilot Feasibility Study in Establishing the Role of UltrasoundGuided Pleural Biopsies in Pleural Infection (The AUDIO Study). Chest 2018;154:766-72.

17. McCauley L, Dean N. Pneumonia and empyema: causal, casual or unknown. J Thorac Dis 2015;7:992-8.

18. Franchetti L, Schumann DM, Tamm M, et al. Multiplex bacterial polymerase chain reaction in a cohort of patients with pleural effusion. BMC Infect Dis 2020;20:99. 
19. Maskell NA, Davies CW, Nunn AJ, et al. U.K. Controlled trial of intrapleural streptokinase for pleural infection. $\mathrm{N}$ Engl J Med 2005;352:865-74.

20. Tsang KY, Leung WS, Chan VL, et al. Complicated parapneumonic effusion and empyema thoracis: microbiology and predictors of adverse outcomes. Hong Kong Med J 2007;13:178-86.

21. Tu CY, Hsu WH, Hsia TC, et al. The changing pathogens of complicated parapneumonic effusions or empyemas in a medical intensive care unit. Intensive Care Med 2006;32:570-6.

22. Lin YC, Chen HJ, Liu YH, et al. A 30-month experience of thoracic empyema in a tertiary hospital: emphasis on differing bacteriology and outcome between the medical intensive care unit (MICU) and medical ward. South Med J 2008;101:484-9.

23. Vaudaux P, Waldvogel FA. Gentamicin inactivation in purulent exudates: role of cell lysis. J Infect Dis 1980;142:586-93.

24. Chapman SJ, Davies RJ. Recent advances in parapneumonic effusion and empyema. Curr Opin Pulm Med 2004;10:299-304.

25. Davies HE, Merchant S, McGown A. A study of the complications of small bore 'Seldinger' intercostal chest drains. Respirology 2008;13:603-7.

26. Keeling AN, Leong S, Logan PM, et al. Empyema and effusion: outcome of image-guided small-bore catheter drainage. Cardiovasc Intervent Radiol 2008;31:135-41.

27. Rahman NM, Maskell NA, Davies CW, et al. The relationship between chest tube size and clinical outcome in pleural infection. Chest 2010;137:536-43.

28. Moulton JS, Benkert RE, Weisiger KH, et al. Treatment of complicated pleural fluid collections with imageguided drainage and intracavitary urokinase. Chest 1995;108:1252-9.

29. Horsley A, Jones L, White J, et al. Efficacy and complications of small-bore, wire-guided chest drains. Chest 2006;130:1857-63.

30. Matsunuma R, Kase K, Asai N, et al. Drainage using Chest Tubes Smaller than 20 French is Suitable for Patients with Thoracic Empyema. Int J Respir Pulm Med 2016;3:058.

31. Huang HC, Chang HY, Chen CW, et al. Predicting factors for outcome of tube thoracostomy in complicated parapneumonic effusion for empyema. Chest 1999;115:751-6.

32. Rahman NM, Maskell NA, West A, et al. Intrapleural use of tissue plasminogen activator and DNase in pleural infection. N Engl J Med 2011;365:518-26.
33. Davies RJ, Traill ZC, Gleeson FV. Randomised controlled trial of intrapleural streptokinase in community acquired pleural infection. Thorax 1997;52:416-21.

34. Diacon AH, Theron J, Schuurmans MM, et al. Intrapleural streptokinase for empyema and complicated parapneumonic effusions. Am J Respir Crit Care Med 2004;170:49-53.

35. Misthos P, Kokotsakis J, Konstantinou M, et al. Postoperative residual pleural spaces: characteristics and natural history. Asian Cardiovasc Thorac Ann 2007;15:54-8.

36. Bouros D, Schiza S, Tzanakis N, et al. Intrapleural urokinase versus normal saline in the treatment of complicated parapneumonic effusions and empyema. A randomized, double-blind study. Am J Respir Crit Care Med 1999;159:37-42.

37. Cafarotti S, Dall'Armi V, Cusumano G, et al. Small-bore wire-guided chest drains: safety, tolerability, and effectiveness in pneumothorax, malignant effusions, and pleural empyema. J Thorac Cardiovasc Surg 2011;141:683-7.

38. Abusedera M, Alkady O. Ultrasound-guided Pleural Effusion Drainage With a Small Catheter Using the Single-step Trocar or Modified Seldinger Technique. J Bronchology Interv Pulmonol 2016;23:138-45.

39. Tillett WS, Sherry S. The effect in patients of streptococcal fibrinolysin (streptokinase) and streptococcal desoxyribonuclease on fibrinous, purulent, and sanguinous pleural exudations. J Clin Invest 1949;28:173-90.

40. Piccolo F, Pitman N, Bhatnagar R, et al. Intrapleural tissue plasminogen activator and deoxyribonuclease for pleural infection. An effective and safe alternative to surgery. Ann Am Thorac Soc 2014;11:1419-25.

41. Majid A, Kheir F, Folch A, et al. Concurrent Intrapleural Instillation of Tissue Plasminogen Activator and DNase for Pleural Infection. A Single-Center Experience. Ann Am Thorac Soc 2016;13:1512-8.

42. Mehta HJ, Biswas A, Penley AM, et al. Management of Intrapleural Sepsis with Once Daily Use of Tissue Plasminogen Activator and Deoxyribonuclease. Respiration 2016;91:101-6.

43. Altmann ES, Crossingham I, Wilson S, et al. Intrapleural fibrinolytic therapy versus placebo, or a different fibrinolytic agent, in the treatment of adult parapneumonic effusions and empyema. Cochrane Database Syst Rev 2019;2019:CD002312.

44. Popowicz N, Bintcliffe O, De Fonseka D, et al. Dose Deescalation of Intrapleural Tissue Plasminogen Activator Therapy for Pleural Infection. The Alteplase Dose Assessment for Pleural Infection Therapy Project. Ann Am 
Thorac Soc 2017;14:929-36.

45. Alemán C, Porcel JM, Alegre J, et al. Intrapleural Fibrinolysis with Urokinase Versus Alteplase in Complicated Parapneumonic Pleural Effusions and Empyemas: A Prospective Randomized Study. Lung 2015;193:993-1000.

46. Bédat B, Plojoux J, Noel J, et al. Comparison of intrapleural use of urokinase and tissue plasminogen activator/DNAse in pleural infection. ERJ Open Res 2019;5:00084-2019.

47. Hooper CE, Edey AJ, Wallis A, et al. Pleural irrigation trial (PIT): a randomised controlled trial of pleural irrigation with normal saline versus standard care in patients with pleural infection. Eur Respir J 2015;46:456-63.

48. Waite RJ, Carbonneau RJ, Balikian JP, et al. Parietal pleural changes in empyema: appearances at CT. Radiology 1990;175:145-50.

49. Knight PH, Maheshwari N, Hussain J, et al. Complications during intrahospital transport of critically ill patients: Focus on risk identification and prevention. Int J Crit Illn Inj Sci 2015;5:256-64.

50. Solèr M, Wyser C, Bolliger CT, et al. Treatment of early parapneumonic empyema by "medical" thoracoscopy. Schweiz Med Wochenschr 1997;127:1748-53.

51. Brutsche MH, Tassi GF, Györik S, et al. Treatment of sonographically stratified multiloculated thoracic empyema by medical thoracoscopy. Chest 2005;128:3303-9.

52. Ravaglia C, Gurioli C, Tomassetti S, et al. Is medical thoracoscopy efficient in the management of multiloculated and organized thoracic empyema?. Respiration 2012;84:219-24.

53. Kheir F, Thakore S, Mehta H, et al. Intrapleural Fibrinolytic Therapy versus Early Medical Thoracoscopy for Treatment of Pleural Infection. Randomized Controlled Clinical Trial. Ann Am Thorac Soc 2020;17:958-64.

54. Towe CW, Carr SR, Donahue JM, et al. Morbidity and 30-day mortality after decortication for parapneumonic empyema and pleural effusion among patients in the Society of Thoracic Surgeons' General Thoracic Surgery Database. J Thorac Cardiovasc Surg 2019;157:1288-1297.e4.

55. Nayak R, Brogly SB, Lajkosz K, et al. Outcomes of Operative and Nonoperative Treatment of Thoracic Empyema: A Population-Based Study. Ann Thorac Surg 2019;108:1456-63.

56. Cordice JW Jr, Cabezon J. Chest trauma with pneumothorax and hemothorax: review of experience with 502 cases. J Thorac Cardiovasc Surg 1965;50:316-38.
57. Azfar Ali H, Lippmann M, Mundathaje U, et al. Spontaneous hemothorax: a comprehensive review. Chest 2008; 134:1056-65.

58. Morgan CK, Bashoura L, Balachandran D, et al. Spontaneous Hemothorax. Ann Am Thorac Soc 2015;12:1578-82.

59. Patrini D, Panagiotopoulos N, Pararajasingham J, et al. Etiology and management of spontaneous haemothorax. J Thorac Dis 2015;7:520-6.

60. Hyacinthe AC, Broux C, Francony G, et al. Diagnostic accuracy of ultrasonography in the acute assessment of common thoracic lesions after trauma. Chest 2012;141:1177-83.

61. Rahimi-Movaghar V, Yousefifard M, Ghelichkhani P, et al. Application of Ultrasonography and Radiography in Detection of Hemothorax; a Systematic Review and MetaAnalysis. Emerg (Tehran) 2016;4:116-26.

62. Kaewlai R, Avery LL, Asrani AV, et al. Multidetector CT of blunt thoracic trauma. Radiographics 2008;28:1555-70.

63. Boersma WG, Stigt JA, Smit HJ. Treatment of haemothorax. Respir Med 2010;104:1583-7.

64. Bauman ZM, Kulvatunyou N, Joseph B, et al. A Prospective Study of 7-Year Experience Using Percutaneous 14-French Pigtail Catheters for Traumatic Hemothorax/Hemopneumothorax at a Level-1 Trauma Center: Size Still Does Not Matter. World J Surg 2018;42:107-13.

65. Cohen NS, Braig Z, Collins JN. Prevalence and Management of Posttraumatic Retained Hemothorax in a Level 1 Trauma Center. Am Surg 2018;84:e369-71.

66. DuBose J, Inaba K, Demetriades D, et al. Management of post-traumatic retained hemothorax: a prospective, observational, multicenter AAST study. J Trauma Acute Care Surg 2012;72:11-22; discussion 22-4; quiz 316.

67. DuBose J, Inaba K, Okoye O, et al. Development of posttraumatic empyema in patients with retained hemothorax: results of a prospective, observational AAST study. J Trauma Acute Care Surg 2012;73:752-7.

68. Hendriksen BS, Kuroki MT, Armen SB, et al. Lytic Therapy for Retained Traumatic Hemothorax: A Systematic Review and Meta-analysis. Chest 2019;155:805-15.

69. Velmahos GC, Demetriades D, Chan L, et al. Predicting the need for thoracoscopic evacuation of residual traumatic hemothorax: chest radiograph is insufficient. J Trauma 1999;46:65-70.

70. Esteban A, Anzueto A, Frutos F, et al. Characteristics and outcomes in adult patients receiving mechanical ventilation: a 28-day international study. JAMA 
2002;287:345-55.

71. Chen KY, Jerng JS, Liao WY, et al. Pneumothorax in the ICU: patient outcomes and prognostic factors. Chest 2002;122:678-83.

72. Noppen M, De Keukeleire T. Pneumothorax. Respiration 2008;76:121-7.

73. Rankine JJ, Thomas AN, Fluechter D. Diagnosis of pneumothorax in critically ill adults. Postgrad Med J 2000;76:399-404.

74. Ebrahimi A, Yousefifard M, Mohammad Kazemi H, et al. Diagnostic Accuracy of Chest Ultrasonography versus Chest Radiography for Identification of Pneumothorax: A Systematic Review and Meta-Analysis. Tanaffos 2014;13:29-40.

75. Lichtenstein DA, Menu Y. A bedside ultrasound sign ruling out pneumothorax in the critically ill. Lung sliding. Chest 1995;108:1345-8.

76. Gilbert TB, McGrath BJ, Soberman M. Chest tubes: indications, placement, management, and complications. J Intensive Care Med 1993;8:73-86.

77. Mentzer SJ, Tsuda A, Loring SH. Pleural mechanics and the pathophysiology of air leaks. J Thorac Cardiovasc Surg 2018;155:2182-9.

78. Havelock T, Teoh R, Laws D, et al. Pleural procedures and thoracic ultrasound: British Thoracic Society Pleural Disease Guideline 2010. Thorax 2010;65 Suppl 2:ii61-76.

79. American College of Surgeons. Committee on Trauma. Advanced Trauma Life Support ${ }^{\circledR}$, ATLS®. Student Course Manual; 2018.

80. Lin YC, Tu CY, Liang SJ, et al. Pigtail catheter for the management of pneumothorax in mechanically ventilated patients. Am J Emerg Med 2010;28:466-71.

81. MacDuff A, Arnold A, Harvey J, et al. Management of spontaneous pneumothorax: British Thoracic Society Pleural Disease Guideline 2010. Thorax 2010;65 Suppl 2:ii18-31.

Cite this article as: Hu K, Chopra A, Kurman J, Huggins JT. Management of complex pleural disease in the critically ill patient. J Thorac Dis 2021;13(8):5205-5222. doi: 10.21037/jtd2021-31
82. Munnell ER. Thoracic drainage. Ann Thorac Surg 1997;63:1497-502.

83. Baumann MH, Strange C, Heffner JE, et al. Management of spontaneous pneumothorax: an American College of Chest Physicians Delphi consensus statement. Chest 2001;119:590-602.

84. Ouellet JF, Trottier V, Kmet L, et al. The OPTICC trial: a multi-institutional study of occult pneumothoraces in critical care. Am J Surg 2009;197:581-6.

85. Kirkpatrick AW, Rizoli S, Ouellet JF, et al. Occult pneumothoraces in critical care: a prospective multicenter randomized controlled trial of pleural drainage for mechanically ventilated trauma patients with occult pneumothoraces. J Trauma Acute Care Surg 2013;74:74754; discussion 754-5.

86. Tocino IM, Miller MH, Fairfax WR. Distribution of pneumothorax in the supine and semirecumbent critically ill adult. AJR Am J Roentgenol 1985;144:901-5.

87. Leigh-Smith S, Harris T. Tension pneumothorax--time for a re-think? Emerg Med J 2005;22:8-16.

88. Brunelli A, Beretta E, Cassivi SD, et al. Consensus definitions to promote an evidence-based approach to management of the pleural space. A collaborative proposal by ESTS, AATS, STS, and GTSC. Eur J Cardiothorac Surg 2011;40:291-7.

89. Hu K, Chopra A, Huggins JT, et al. Pleural manometry: techniques, applications, and pitfalls. J Thorac Dis 2020;12:2759-70.

90. Huggins JT, Maldonado F, Chopra A, et al. Unexpandable lung from pleural disease. Respirology 2018;23:160-7.

91. Austin A, Jogani SN, Brasher PB, et al. The Urinothorax: A Comprehensive Review With Case Series. Am J Med Sci 2017;354:44-53.

92. Sahn SA. Pleural effusions of extravascular origin. Clin Chest Med 2006;27:285-308. 